\title{
Effects of Growing Medium Type and Predator:Prey Ratio on Rove Beetle, Dalotia coriaria (Coleoptera: Staphylinidae), Adult Predation on Fungus Gnat, Bradysia sp. nr. coprophila (Diptera: Sciaridae), Larvae
}

\author{
Nathan J. Herrick and Raymond A. Cloyd ${ }^{1}$ \\ Department of Entomology, Kansas State University, 123 Waters Hall, \\ Manhattan, KS 66506
}

Additional index words. biological control, production practices, greenhouse, plant protection, natural enemy-pest-plant interactions

\begin{abstract}
Fungus gnats, Bradysia spp. (Diptera: Sciaridae), are major insect pests because the larvae can directly damage plants grown in greenhouse production systems. In general, insecticides are commonly used to suppress fungus gnat larval populations. However, the rove beetle, Dalotia coriaria (Kraatz) (Coleoptera: Staphylinidae), a commercially available predator of insect pests, including fungus gnat larvae, may be an alternative to using insecticides. Growing medium selection used for growing plants can influence insect pest and predator interactions in greenhouse production systems; however, quantitative information is limited. Therefore, we conducted greenhouse experiments and a laboratory experiment to determine the effects of growing medium type on $D$. coriaria adult predation and fungus gnat, Bradysia. sp. nr. coprophila (Lintner) (Diptera: Sciaridae), larval survival when feeding on the roots of coleus, Solenostemon scutellarioides (L.) Codd, plants. In addition, experiments were conducted to determine the number of rove beetle adults, based on predator:prey ratios, needed to regulate fungus gnat larval populations. In all three experiments, fewer fungus gnat larvae survived in Pro-Mix BX than the Berger BM1 growing medium, and rove beetles reduced the number of fungus gnat larvae in both growing media in the greenhouse experiments. Although predator:prey ratio was not significant, we found that 10 rove beetle adults per 15.2-cm diameter container $\left(1834.82 \mathrm{~cm}^{3}\right.$ with $2.0 \mathrm{~L}$ of growing medium) regulated fungus gnat larval populations at the densities investigated. Therefore, greenhouse producers should consider the effects of production practices, such as growing medium type, when using rove beetles to regulate fungus gnat larval populations.
\end{abstract}

Fungus gnat, Bradysia sp. nr. coprophila (Lintner) (Diptera: Sciaridae), larvae can damage plants grown in greenhouse production systems, especially during propagation (Cloyd, 2000). Fungus gnat larvae feed on plant roots, which inhibits the uptake of water and nutrients. In addition, larval feeding creates wounds that can allow entry of soilborne plant pathogens (Gardiner et al., 1990; Gillespie and Menzies, 1993; Hungerford,

Received for publication 5 June 2018. Accepted for publication 1 Aug. 2018.

We thank Mary Beth Kirkham, Department of Agronomy, and Jeff Whitworth, Department of Entomology, at Kansas State University (Manhattan, KS) for reviewing an initial draft of the manuscript. We also thank three anonymous reviewers for their feedback, which enhanced the quality of the manuscript.

${ }^{1}$ Corresponding author. E-mail: rcloyd@ksu. edu.
1916; Jarvis et al., 1993; Wilkinson and Daugherty, 1970). Drench applications of insect growth regulators, contact insecticides, or microbial insecticides are the primary means used by greenhouse producers to suppress populations of fungus gnat larvae (Cloyd and Dickinson, 2006; Lindquist, 1994). Biological control, or the use of natural enemies, affords greenhouse producers an alternative plant-protection strategy to regulate fungus gnat populations in greenhouse production systems. The common biological control agents used against fungus gnat larvae in container greenhouse production systems are entomopathogenic nematodes (e.g., Steinernema feltiae), predatory mites (e.g., Stratiolaelaps scimitus), and predatory rove beetles (Carney et al., 2002; Echegaray et al., 2015; Gouge and Hague, 1995; Harris et al., 1995; Wright and Chambers, 1994).

The rove beetle, Dalotia coriaria (Kraatz) (Coleoptera: Staphylinidae), is a commercially available predator of greenhouse insect pests, including fungus gnat larvae, that resides in the growing medium (Echegaray et al., 2015; Helyer et al., 2003). Birken and Cloyd (2007) reported that rove beetle adults will feed on fungus gnat larvae under laboratory conditions. Nonetheless, greenhouse production practices may influence the effectiveness of biological control agents. For instance, Herrick and Cloyd (2017) found that growing medium type can affect predation by $D$. coriaria adults under greenhouse and laboratory conditions. However, minimal information exists on the impact of production practices, such as the use of different growing media, and how growing media affect $D$. coriaria adult predation and survival of fungus gnat larvae, which could impact the success of biological control programs. Studies have been conducted to determine appropriate predator:prey ratios for belowground pests, such as fungus gnats (Echegaray et al., 2015), to increase the effectiveness of biological control agents in regulating pest populations.

Physical and structural characteristics of a growing medium can influence insect movement and distribution (Grez and Villagrán, 2000). Growing medium properties (e.g., composition) may significantly influence the distribution of insects within a growing medium (Kindvall et al., 2000; Riis and Esbjerg, 1998). In addition, growing medium type may affect the movement of predatory arthropods (insects and mites) (Miklasiewicz et al., 2002; Pacchioli and Hower, 2004), thus influencing predation efficacy. As such, growing medium may directly or indirectly affect rove beetle predation and/or fungus gnat larval survival (Echegaray et al., 2015; Lindquist et al., 1985; Pacchioli and Hower, 2004).

Therefore, the following study was conducted to determine the effects of two commercially available growing media on predation by adult rove beetles and survival of fungus gnat larvae when feeding on coleus, Solenostemon scutellarioides L. Codd, roots under greenhouse and laboratory conditions. The goal of our study was to obtain information associated with production practices, such as selection of growing media, which will help greenhouse producers enhance predation by adult rove beetles and, thus, better manage fungus gnat larvae in greenhouse production systems.

\section{Materials and Methods}

The following study involved experiments conducted in a greenhouse and laboratory using different growing medium types and predator:prey ratios. The first greenhouse experiment varied the density of rove beetle adults while maintaining a constant fungus gnat larval density. It was designed to determine whether predator:prey ratios of $0: 20$, $1: 4,1: 2$, and $1: 1.3$, would affect fungus gnat larval survival in containers with coleus plants grown in two different growing media. The second greenhouse experiment varied the density of fungus gnat larvae while 
maintaining a constant density of adult rove beetles at predator:prey ratios of $0: 20,1: 1.5$, $1: 2$, and $1: 2.5$ in containers with coleus plants grown in the same two growing media. In addition, the effect of growing medium on survival of fungus gnat larvae was determined in the laboratory.

Greenhouse experiment: Varied densities of rove beetle adults. The first greenhouse experiment was conducted from 2 Nov. to 8 Dec. 2017. A laboratory colony of the fungus gnat, Bradysia sp. nr. coprophila, was maintained in $8.0-\mathrm{L}$ plastic containers with tightsealing lids. Openings were perforated into the lids $(11 \times 21 \mathrm{~cm})$ and insect screening $(0.2 \times 0.8 \mathrm{~mm}$; Green-tek, Edgerton, WI) was fastened to the lids with hot glue for ventilation. Berger BM1 All-Purpose Mix (Berger, Saint-Modeste, Quebec, Canada) growing medium composed of $75 \%$ to $85 \%$ coarse sphagnum peatmoss, perlite, and vermiculite was moistened in a $6.0-\mathrm{L}$ plastic container with $\approx 450 \mathrm{~mL}$ of tap water. The growing medium surface was moistened with an additional $100 \mathrm{~mL}$ of tap water using a 946-mL plastic spray bottle (SprayMaster; Delta Industries, King of Prussia, PA) to prevent the growing medium from being charred during pasteurization. The moistened growing medium was then pasteurized in a microwave (Panasonic Inverter; Panasonic Consumer Electronics Comp., Newark, NJ) at $1250 \mathrm{~W}$ for $20 \mathrm{~min}$, which increased the internal temperature of the growing medium to $\approx 100{ }^{\circ} \mathrm{C}$. The growing medium was then allowed to cool with the addition of $1.6 \mathrm{~L}$ of tap water. Two potatoes (240 g), Solanum tuberosum L., were placed into boiling water for $10 \mathrm{~min}$, pureed into small particles using a food processor and tap water $(125 \mathrm{~mL})$, and then uniformly mixed into the growing medium by hand. About $2.5 \mathrm{~L}$ of the growing medium and potato mixture were placed inside the 8.0-L container.

About $60 \mathrm{~g}$ of oats, Avena sativa L. (The Quaker Oats Company, Chicago, IL), were placed into two piles positioned in opposite corners of the containers on the growing medium surface, and then moistened with $50 \mathrm{~mL}$ of tap water using a $946-\mathrm{mL}$ plastic spray bottle. About 1000 adult fungus gnats (mixture of males and females) were aspirated into a 9-dram (33-mL) plastic vial from the main colony and released into the containers for oviposition (egg-laying). After all adults died $(\approx 2-3 \mathrm{~d})$, the growing medium and oats in the containers were moistened daily with $50 \mathrm{~mL}$ of tap water using a $946-\mathrm{mL}$ plastic spray bottle. The colony was maintained at $25 \pm 5{ }^{\circ} \mathrm{C}, 50 \%$ to $60 \%$ relative humidity, and constant light in a laboratory in the Department of Entomology at Kansas State University (Manhattan, KS).

To isolate second and third instar fungus gnat larvae for use in the experiment, a glass petri dish $(100 \times 15 \mathrm{~mm})$ was lined with $9-\mathrm{cm}$ diameter P8 Fisherbrand filter paper (Fisher Scientific, Pittsburgh, PA) and placed into a 750-mL plastic food storage container. About $9.5 \mathrm{~g}$ of growing medium with pureed potato was placed on top of the filter paper and moistened with tap water using a plastic spray bottle, avoiding any standing water. The lid was placed on the storage container. Adult fungus gnats [1:9 (male:female ratio) (R.A. Cloyd, personal observation)] were aspirated into 9-dram plastic vials from the main colony, released into the containers so that mated females could lay eggs, and then given 10 to $11 \mathrm{~d}$ for the larvae to eclose from eggs and develop into second to early third instars before use in the experiment.

Adult rove beetles, $D$. coriaria, used in the experiment were maintained similar to the fungus gnats; however, no potato was added to the growing medium and about $200 \mathrm{~g}$ of moistened oats were placed in the center of the containers on the growing medium surface. The colony was maintained at $25 \pm 5^{\circ} \mathrm{C}$, $50 \%$ to $60 \%$ relative humidity, and constant darkness.

Coleus, Solenostemon scutellarioides (cv. Red Head), plants used in the experiment were initially purchased as plugs (i.e., young plants - either seedlings or cuttings grown as single units in modular trays) from Proven Winners, LLC (Sycamore, IL) and transplanted into $15.2-\mathrm{cm}$ containers. Twenty plugs were transplanted into containers with Berger BM1 All-Purpose Mix growing medium. Another 20 plugs were transplanted into containers with Pro-Mix BX General Purpose (Premier Horticulture, Inc., Quakertown, PA) growing medium composed of $75 \%$ to $85 \%$ Canadian peatmoss, perlite, vermiculite, and dolomitic and calcitic limestone. All 40 coleus plants were randomly arranged on a wire-mesh bench about $20 \mathrm{~cm}$ apart and allowed to establish for $35 \mathrm{~d}$ at $23 \pm$ $3{ }^{\circ} \mathrm{C}$ and a relative humidity of $50 \%$ to $60 \%$. The plants were irrigated with $500 \mathrm{~mL}$ of tap water every $2 \mathrm{~d}$. The experiment was set up as a completely randomized design with two growing media and four predator:prey ratios. There were eight treatments, including two controls (no rove beetle adults) with five replications per treatment (Table 1).

After the 35-d plant-establishment period, plant height and number of leaves were recorded to determine whether there were any differences in plant growth associated with the two growing media. Also, the aboveground portions (leaves and stems) were excised at the base of each plant just above the growing medium surface, leaving the coleus roots intact as a food source for fungus gnat larvae. On the same day, forty 9-dram plastic vials were prepared in the laboratory. Twenty plastic vials contained $\approx 10 \mathrm{~mL}$ of moistened Berger BM1 and another 20 plastic vials contained $10 \mathrm{~mL}$ of moistened ProMix BX. About $1 \mathrm{~g}$ of growing medium was gently removed from the containers that were previously set up to isolate second to third instar fungus gnat larvae (described previously) using a metal spatula and placed into a 5-cm glass petri dish. The growing medium in the petri dish was saturated with tap water using a 500-mL Easy-Squeeze Wash Bottle (Fisher Scientific) to separate the fungus gnat larvae from the growing medium. To prevent mortality, larvae were not immersed in water longer than $3 \mathrm{~min}$. Then, under a dissecting microscope (Nikon SMZ1000; BioQuip Products, Inc., Rancho Dominguez, CA) and using a 14.6-cm glass pasteur pipette (Fisherbrand; Fisher Scientific), 20 second to third instar fungus gnat larvae were transferred onto the growing medium surface in each of the 40 plastic vials. Lids were placed on the plastic vials, which were transported to the greenhouse where the fungus gnat larvae were released onto the growing medium surface of all the treatments. The containers with growing medium and fungus gnat larvae were placed into 3.8-L Ziploc plastic resealable bags (SC Johnson, Racine, WI), which kept the moisture level of the growing medium constant (Herrick and Cloyd, 2017). In addition, 40 holes were perforated in the top of each Ziploc bag with a probing needle to allow for ventilation and reduce condensation. Larvae were allowed to acclimate for $24 \mathrm{~h}$.

After $24 \mathrm{~h}$, same-aged (i.e., 24-h posteclosion) rove beetle adults were aspirated from the colony, simulating conditions similar to a greenhouse producer ordering rove beetles from a biological control supplier. The sex ratio was 1:1 (female:male). Rove beetle adults were released into the containers onto the surface of the growing medium at the appropriate predator:prey ratio, based on the aforementioned treatments: no rove beetle adults $(0: 20), 5$ rove beetle adults (1:4), 10 rove beetle adults (1:2), and 15 rove beetle adults $(1: 1.3)$.

After $15 \mathrm{~d}$, a 5- $\times 4$-cm section of a yellow sticky card, with one side of the adhesive exposed, was placed on the edge of the container at a $45^{\circ}$ angle to the growing medium surface, with the sticky surface facing upwards. The number of fungus gnat adults captured on each yellow sticky card was recorded after $20 \mathrm{~d}$, which was an indirect assessment of fungus gnat larval mortality (i.e., the number of fungus gnat larvae initially released minus the number of fungus gnat adults captured on the yellow sticky cards). Each Ziploc bag was also rinsed with tap water into a white, 10-L plastic container to account for any fungus gnat adults that adhered to the condensate.

Greenhouse experiment: Varied densities of fungus gnat larvae. The second greenhouse experiment, which was similar to the first greenhouse experiment described previously, was conducted from 8 Jan. to $13 \mathrm{Feb}$. 2018. However, in this experiment, the number of rove beetle adults released was held constant whereas the number of fungus gnat larvae released varied (Table 2).

Laboratory experiment. A laboratory experiment was conducted from 7 Mar. to 6 Apr. 2018 in the Department of Entomology at Kansas State University to determine whether coleus roots affect fungus gnat larval survival compared with pureed potato, using the same two growing media. We wanted to determine whether coleus roots were a sufficient food source for fungus gnat larval survival. In addition, we wanted to assess whether any reductions in adult captures on 
Table 1. Growing media, number of rove beetle Dalotia coriaria adults, number of fungus gnat Bradysia sp. nr. coprophila larvae, and predator:prey ratio used to determine the effect of growing medium on rove beetle adult predation and fungus gnat larval survival under greenhouse conditions.

\begin{tabular}{lccc}
\hline Growing media & $\begin{array}{c}\text { Number of Dalotia } \\
\text { coriaria } \text { adults }\end{array}$ & $\begin{array}{c}\text { Number of Bradysia sp. } \\
\text { nr. coprophila larvae }\end{array}$ & Predator:prey ratio \\
\hline Berger BM1 & 0 & 20 & $0: 20$ \\
Pro-Mix BX & 0 & 20 & $0: 20$ \\
Berger BM1 & 5 & 20 & $1: 4$ \\
Pro-Mix BX & 5 & 20 & $1: 4$ \\
Berger BM1 & 10 & 20 & $1: 2$ \\
Pro-Mix BX & 10 & 20 & $1: 2$ \\
Berger BM1 & 15 & 20 & $1: 1.3$ \\
Pro-Mix BX & 15 & 20 & $1: 1.3$ \\
\hline
\end{tabular}

Table 2. Growing media, number of rove beetle Dalotia coriaria adults, number of fungus gnat Bradysia sp. nr. coprophila larvae, and predator:prey ratio used to determine the effect of growing medium on rove beetle adult predation and fungus gnat larval survival under greenhouse conditions.

\begin{tabular}{lccc}
\hline Growing media & $\begin{array}{c}\text { Number of } \\
\text { Dalotia coriaria } \text { adults }\end{array}$ & $\begin{array}{c}\text { Number of Bradysia sp. } \\
\text { nr. coprophila larvae }\end{array}$ & Predator:prey ratio \\
\hline Berger BM1 & 0 & 20 & $0: 20$ \\
Pro-Mix BX & 0 & 20 & $0: 20$ \\
Berger BM1 & 10 & 15 & $1: 1.5$ \\
Pro-Mix BX & 10 & 15 & $1: 1.5$ \\
Berger BM1 & 10 & 20 & $1: 2$ \\
Pro-Mix BX & 10 & 20 & $1: 2$ \\
Berger BM1 & 10 & 25 & $1: 2.5$ \\
Pro-Mix BX & 10 & 25 & $1: 2.5$ \\
\hline
\end{tabular}

the yellow sticky cards were due to growing medium type and/or rove beetle adults and not associated with lack of food or extrinsic biological factors, such as insects, mites, bacteria, or fungi preexisting in the unpasteurized growing media used in the greenhouse experiments.

Coleus (cv. Red Head) plants were purchased as plugs from Proven Winners, LLC and transplanted into $15.2-\mathrm{cm}$ containers. Five plugs were transplanted into containers with Berger BM1 and another five plugs were transplanted into containers with Pro-Mix BX. All 10 coleus plants were randomly arranged on a wire-mesh bench $\approx 20 \mathrm{~cm}$ apart and allowed to establish for $35 \mathrm{~d}$ at $23 \pm 3{ }^{\circ} \mathrm{C}$ and a relative humidity of $50 \%$ to $60 \%$. The plants were irrigated with $500 \mathrm{~mL}$ of tap water every $2 \mathrm{~d}$.

After the 35-d establishment period, the plants were excised at the base and the plugs, with accompanying root system, were removed from the containers, placed into Ziploc bags for each growing medium, and transported back to the laboratory for further processing. Using a 6.0 -L plastic container, Berger BM1 was initially moistened with $\approx 450 \mathrm{~mL}$ of tap water, and the growing medium surface was moistened again with $100 \mathrm{~mL}$ of tap water using a 946-mL plastic spray bottle. Five plugs with their accompanying root systems were placed into the growing medium associated with coleus plants grown in Berger BM1. The moistened growing medium with plugs was then pasteurized in a microwave at $1250 \mathrm{~W}$ for 20 min, which increased the internal temperature of the growing medium to about $100{ }^{\circ} \mathrm{C}$. The growing medium was then allowed to cool with the addition of $1.6 \mathrm{~L}$ of tap water.

The aforementioned procedure was repeated with plugs from coleus plants grown in Pro-Mix BX. Pasteurization eliminated any potential extrinsic biological factors such as insects, mites, bacteria, or fungi that could have influenced survival of fungus gnat larvae and adult captures on the yellow sticky cards (Herrick and Cloyd, preliminary data). Extrinsic biological factors could affect the results associated with the greenhouse experiment, making it difficult to determine whether growing medium composition or rove beetle adults impacted fungus gnat larval survival.

Five 473-mL deli containers with lids modified with insect screening $(0.2 \times$ $0.8 \mathrm{~mm}$; Green-tek) to allow for ventilation were filled with $\approx 300 \mathrm{~mL}$ of Berger BM1. One plug from the coleus plants grown in Berger BM1 in the greenhouse was inserted into the deli container. The plug was placed into the growing medium of each deli container with only the top exposed. A dissecting probe was used to perforate the bottom of each deli container, creating 12 holes that allowed any excess water to drain or be reabsorbed by the growing medium. The growing medium was moistened with an additional $70 \mathrm{~mL}$ of tap water using a 946$\mathrm{mL}$ plastic spray bottle. This procedure was repeated with plugs from the coleus plants grown in Pro-Mix BX, using the pasteurized growing medium. Furthermore, a second group of plants (replicates) was set up using the same two growing media but pureed potato was used as a food source for fungus gnat larvae instead of a coleus plug with roots to simulate conditions used for rearing (refer to the section "Greenhouse experiment: Varied densities of rove beetle adults").

After setting up the $473-\mathrm{mL}$ deli containers, 20 second to third instar fungus gnat larvae were isolated as described previously in the section "Greenhouse experiment: Varied densities of rove beetle adults" and placed into each deli container. A 5- $\times 4-\mathrm{cm}$ section of a yellow sticky card was fastened to the lid of each deli container with hot glue, and each container was placed into a plastic petri dish $(1.5 \times 14 \mathrm{~cm})$. Containers and petri dishes were placed into 30-L Sterilite containers (Sterilite Corp., Townsend, MA) in groups of five (according to each treatment), covered with two sheets of newspaper, and the container lids (with six $0.5-\mathrm{cm}$ holes equally spaced) were replaced. Containers were maintained at $23 \pm 5{ }^{\circ} \mathrm{C}$ and under constant light. After $35 \mathrm{~d}$, each section of the yellow sticky card was inspected and the number of fungus gnat adults captured was recorded. Captured adults provided an indirect assessment of larval mortality. The experiment was set up as a completely randomized design with four treatments and five replications per treatment. The treatments were Berger BM1 or Pro-Mix BX with pureed potato or a coleus plug with roots.

Data analysis. Data were analyzed using analysis of variance (ANOVA, $P=0.05$ ) (SAS Institute, 2012) with growing medium type and the number of rove beetle adults released or number of fungus gnat larvae inoculated into the growing medium as the main effects, as well as plant height and the number of leaves as separate dependent variables. Plant height and number of leaves (dependent variables) were tested only against growing medium type (main effect) and not number of rove beetle adults. The data for each experiment (greenhouse and laboratory) conformed to the assumptions of ANOVA, based on normality and homogeneity of variances (Little and Hills, 1978). Data were normally distributed so no transformation procedure was required. Individual treatment means were separated using a Fisher's least significant difference test when ANOVA indicated a significant treatment effect.

\section{Results}

Greenhouse experiment: Varied densities of rove beetle adults. Growing medium type did not significantly affect plant height $(F=$ $0.09 ; \mathrm{df}=1,10 ; P=0.76$ ) or number of leaves $(F=0.84 ; \mathrm{df}=1,10 ; P=0.38)$ of the coleus plants. Plants grown in Berger BM1 were $8.6 \pm$ $0.7 \mathrm{~cm}$ (mean \pm standard error of the mean) in height with $15.4 \pm 1.1$ leaves and the plants grown in Pro-Mix BX were $8.8 \pm 0.5 \mathrm{~cm}$ in height with $16.6 \pm 1.2$ leaves. Growing medium type significantly $(F=7.08$; df $=1$, $5 ; P=0.011)$ affected the number of fungus gnat adults captured on the yellow sticky cards, with significantly more fungus gnat adults captured from Berger BM1 (8.0 \pm 1.5$)$ than Pro-Mix BX (3.6 \pm 0.5$)$. In addition, all rove beetle adult treatments significantly decreased the number of fungus gnat adults $(3.9 \pm$ $0.5)$ captured from the growing medium compared with the control $(11.5 \pm 1.5)(F=$ $7.33 ; \mathrm{df}=3,7 ; P=0.0007)$. However, there were no significant differences in the number of fungus gnat adults captured among the rove beetle adult treatments of $5(5.1 \pm 0.9)$, $10(2.6 \pm 0.9)$, or $15(3.9 \pm 0.9)$. There was 
a significant treatment $\times$ growing medium type interaction $(F=6.19 ; \mathrm{df}=3,11 ; P=$ 0.002 ), where Pro-Mix BX alone reduced fungus gnat adult captures on the yellow sticky cards. However, there was no significant interaction between rove beetle adult treatment and growing medium type for Berger BM1 (Fig. 1).

Greenhouse experiment: Varied densities of fungus gnat larvae. Growing medium type did not significantly affect plant height $(F=$ $0.23 ; \mathrm{df}=1,10 ; P=0.64$ ) or number of leaves $(F=0.26 ; \mathrm{df}=1,10 ; P=0.61)$ of the coleus plants. Plants grown in Berger BM1 were $12.5 \pm 0.4 \mathrm{~cm}$ in height with $19.8 \pm 0.8$ leaves and plants grown in Pro-Mix BX were $12.7 \pm$ $0.3 \mathrm{~cm}$ in height with $19.4 \pm 0.9$ leaves. Growing medium type significantly $(F=$ $4.47 ; \mathrm{df}=1,5 ; P=0.041)$ affected the number of fungus gnat adults captured on the yellow sticky cards, with significantly more fungus gnat adults captured from Berger BM1 $(6.4 \pm 1.3)$ than Pro-Mix BX $(3.0 \pm 0.6)$. In addition, all rove beetle adult treatments significantly decreased the number of fungus gnat adults captured from the growing medium $(2.3 \pm 0.4)$ compared with the control $(11.3 \pm 1.7)(F=17.7 ; \mathrm{df}=3,7$; $P<0.0001)$. Nonetheless, there was no significant difference in the number of fungus gnat adults captured among the fungus gnat treatments of $15(1.4 \pm 0.4), 20(2.9 \pm 0.9)$, or 25 $(3.1 \pm 0.7)$ in which 10 rove beetle adults were released. There was a significant treatment $\times$ growing medium type interaction $(F=$ $6.92 ; \mathrm{df}=3,11 ; P=0.0012)$, where Pro-Mix $\mathrm{BX}$ and rove beetle adults reduced fungus gnat adult captures on yellow sticky cards. However, there was no significant interaction between rove beetle adult treatment and growing medium type for Berger BM1 (Fig. 2).

Laboratory experiment. The food source provided to fungus gnat larvae significantly $(F=7.97 ; \mathrm{df}=1,5 ; P=0.013)$ affected the number of fungus gnat adults captured on the yellow sticky cards based on the number of fungus gnat adults captured from the pasteurized growing medium. Significantly more fungus gnat adults were captured on the yellow sticky cards from the growing medium containing pureed potato $(15.1 \pm 1.3)$ than the growing medium containing a coleus plug with roots $(10.1 \pm 1.1)$. Furthermore, growing medium type significantly $(F=9.04$; $\mathrm{df}=1,5 ; P=0.0094)$ affected the number of fungus gnat adults captured on the yellow sticky cards, with significantly more fungus gnat adults captured on the yellow sticky cards from Berger BM1 (15.2 \pm 1.3$)$ than ProMix BX $(10.0 \pm 1.1)$. There was also a significant treatment $\times$ growing medium type interaction $(F=13.38 ; \mathrm{df}=3,7 ; P=0.0004)$, in which Pro-Mix BX and the coleus plug reduced fungus gnat adult captures on the yellow sticky cards in the Pro-Mix BX treatment. However, fewer fungus gnat adults were captured on the yellow sticky cards associated with the coleus plugs in Berger BM1 compared with the pureed potato (Fig. 3).

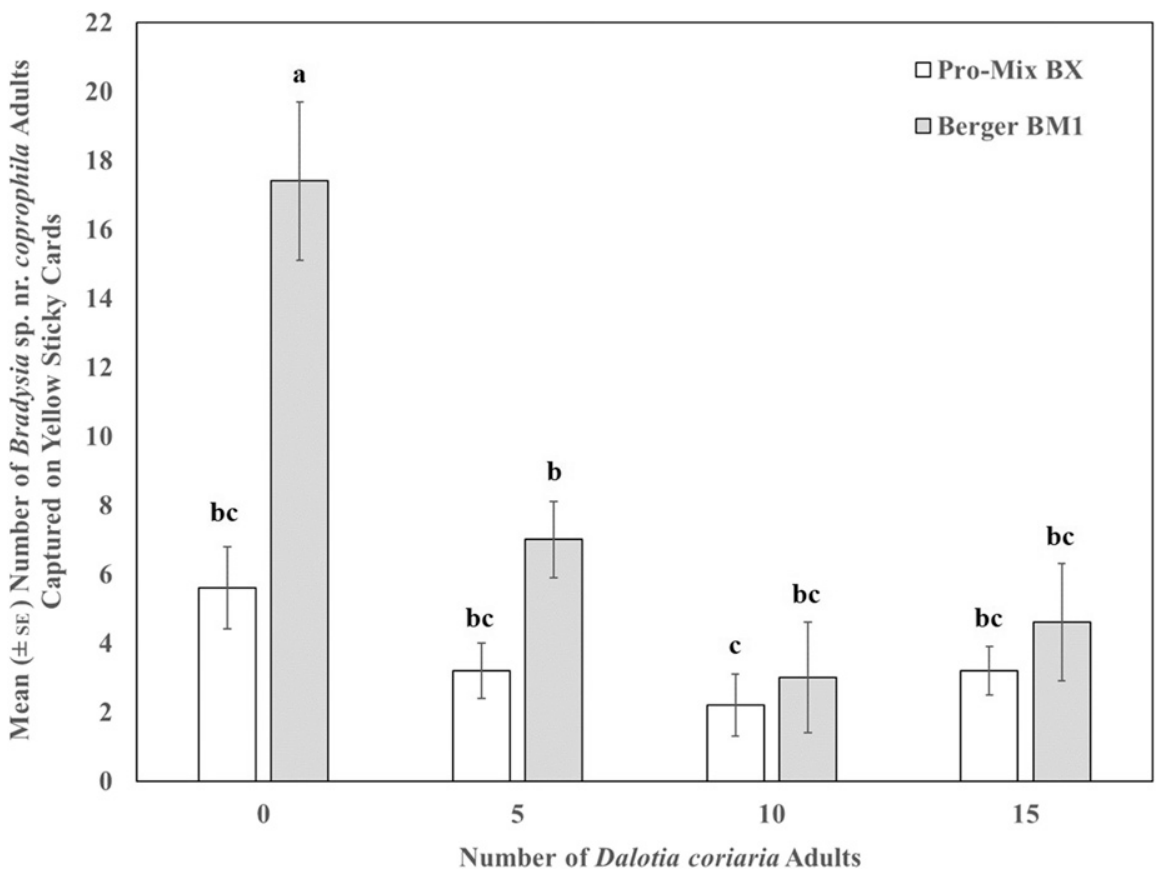

Fig. 1. Mean ( $\pm \mathrm{SE})$ number of fungus gnat, Bradysia sp. nr. coprophila, adults captured on yellow sticky cards from Berger BM1 All-Purpose Mix (Berger BM1) and Pro-Mix BX General Purpose (Pro-Mix BX) growing medium when exposed to 0 (control; no rove beetle adults), 5, 10, or 15 rove beetle, Dalotia coriaria, adults. Means followed by the same letter are not significantly different $(P>0.05)$ as determined by a Fisher's least significance difference mean separation test at $\alpha=0.05$. Vertical bars represent the standard error (SE).

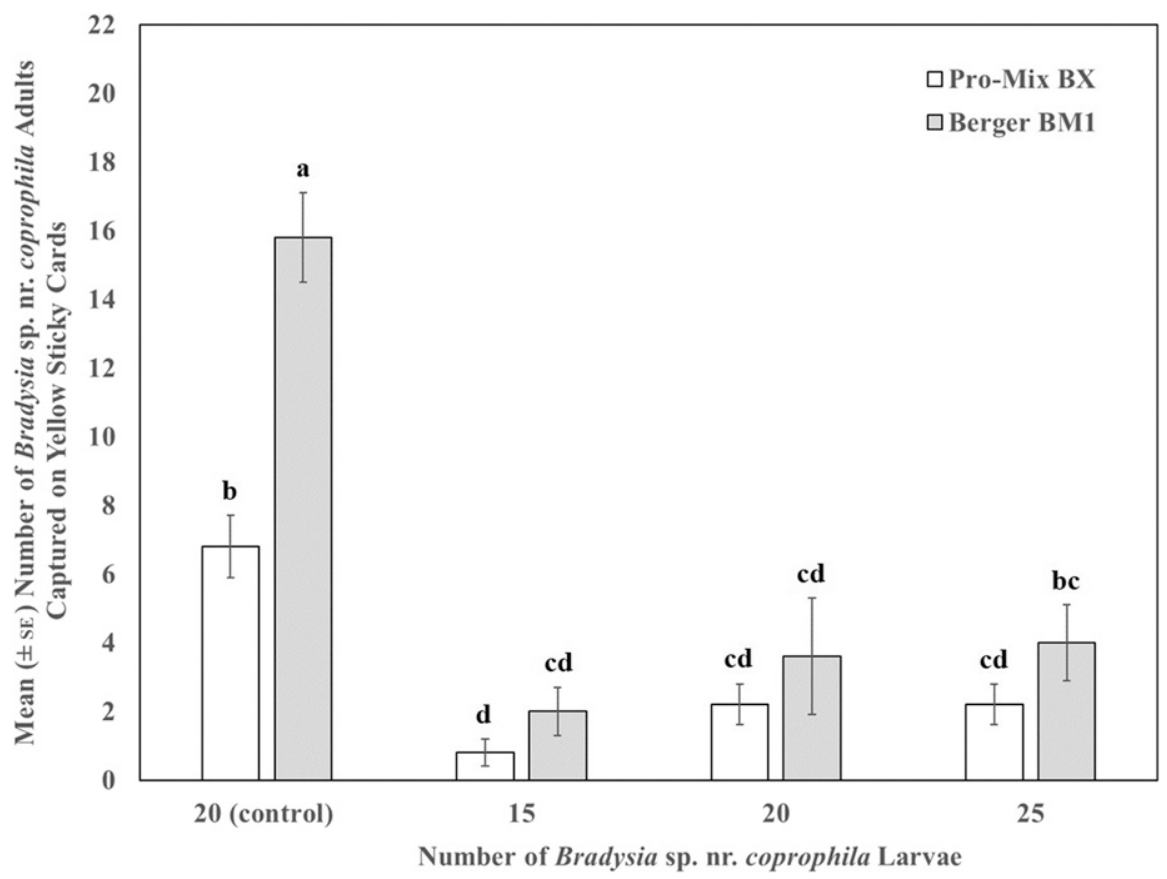

Fig. 2. Mean ( $\pm \mathrm{SE}$ ) number of fungus gnat, Bradysia sp. nr. coprophila, adults captured on yellow sticky cards from Berger BM1 All-Purpose Mix (Berger BM1) and Pro-Mix BX General Purpose (Pro-Mix $\mathrm{BX}$ ) growing medium associated with fungus gnat larval densities of 20 (control; no rove beetle adults), 5, 20, or 25 when exposed to 10 rove beetle, Dalotia coriaria, adults. Means followed by the same letter are not significantly different $(P>0.05)$ as determined by a Fisher's least significance difference mean separation test at $\alpha=0.05$. Vertical bars represent the standard error (SE).

\section{Discussion}

This study is an extension of Herrick and Cloyd (2017), where both studies have demonstrated that growing medium type can influence rove beetle adult predation and fungus gnat larval survival. However, in the current study, we investigated predator:prey ratio and predator numbers, as well as growing medium type. 


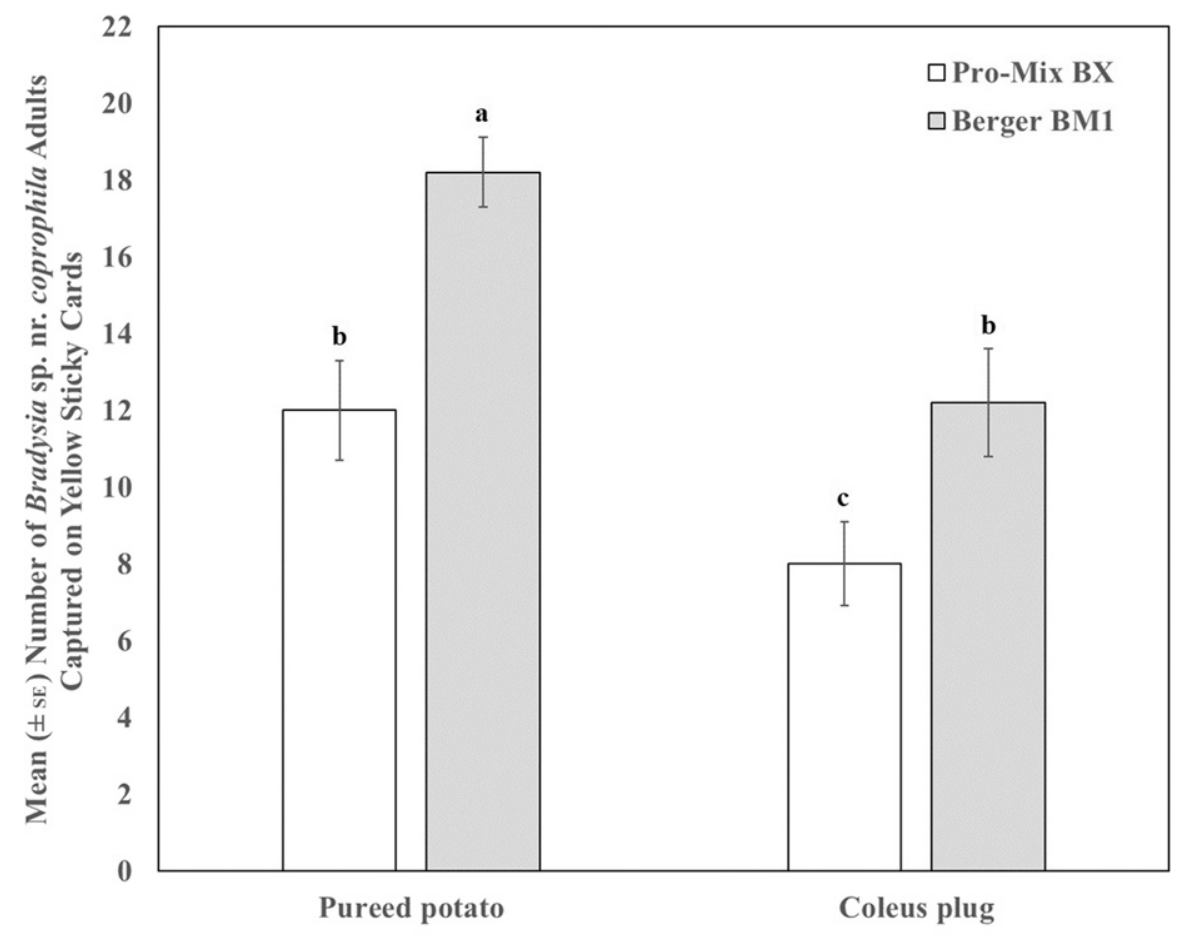

Treatment

Fig. 3. Mean ( $\pm \mathrm{SE})$ number of fungus gnat, Bradysia sp. nr. coprophila, adults captured on yellow sticky cards from pasteurized Berger BM1 All-Purpose Mix (Berger BM1) and Pro-Mix BX General Purpose (Pro-Mix BX) growing medium containing either pureed potato or a coleus, Solenostemon scutellarioides (cv. Red Head), plug with roots. Means followed by the same letter are not significantly different $(P>0.05)$ as determined by a Fisher's least significance difference mean separation test at $\alpha=$ 0.05 . Vertical bars represent the standard error $(\mathrm{SE})$.

The physical and structural characteristics of a growing medium can influence insect movement and distribution (Grez and Villagrán, 2000). Insect movement can be inhibited by soil type and structure (Gustin and Schumacher, 1989; MacDonald and Ellis, 1990). In addition, growing medium properties (e.g., composition) may significantly impact the distribution of insects within a growing medium (Kindvall et al., 2000; Riis and Esbjerg, 1998). For instance, Bykova and Blatt (2018) found that soil type negatively affected the movement of the carrot weevil, Listronotus oregonensis LeConte (Coleoptera: Curculionidae).

Furthermore, growing medium type, depending on composition, may influence the movement of predatory arthropods (insects and mites) (Miklasiewicz et al., 2002; Pacchioli and Hower, 2004), which could influence predation efficacy. As such, growing medium may directly or indirectly affect rove beetle predation and/or fungus gnat larval survival (Echegaray et al., 2015; Lindquist et al., 1985; Pacchioli and Hower, 2004). It is possible that growing medium composition (based on the overall components) may impact the interactions associated with rove beetle adults and fungus gnat larvae.

Herrick and Cloyd (2017) indicated that searching area could affect predation by rove beetle adults. For example, Echegaray et al. (2015) reported that four rove beetle adults provided better control of fungus gnat larvae than two rove beetle adults; however, experiments were conducted in 473-mL deli containers $\left(616.14 \mathrm{~cm}^{3}\right.$ with $0.3 \mathrm{~L}$ of growing medium), which is a smaller searching area than the $15.2-\mathrm{cm}$ diameter containers (1834.82 $\mathrm{cm}^{3}$ with $2.0 \mathrm{~L}$ of growing medium) used in the current study. Furthermore, in our study, we also used more rove beetle adults, which eliminated searching area as a potential factor that appeared to influence the results found in Herrick and Cloyd (2017).

Predation efficacy is important in selecting biological control agents (Farhadi et al., 2011). Therefore, evaluating predator:prey ratios and assessing the number of predators to release will result in greater levels of predation and consequently enhance the success of augmentative biological control programs (Amoah et al., 2016; Echegaray et al., 2015). Studies have been conducted to determine appropriate predator:prey ratios for aboveground (Cheng et al., 2012; Gaudchau, 1982; Gilkeson and Hill, 1987; Opit et al., 2004) and belowground pests (Echegaray et al., 2015) to increase the effectiveness of biological control agents. Moreover, different initial prey numbers at a given predator: prey ratio also may influence rove beetle adult predation (Echegaray et al., 2015; Opit et al., 2004).

In our study, we found no significant differences in the predator:prey ratios; however, in the second greenhouse experiment, 10 rove beetle adults regulated fungus gnat larval populations regardless of the number of fungus gnat larvae. It is important to determine an appropriate number of rove beetle adults to release to avoid mutual interference, which is a common phenomenon that occurs under conditions of low prey availability or a high predator density (Hassell et al., 1976). In addition, cannibalism can occur under high predator densities (Miller and Williams, 1983). Therefore, the information obtained from our study will help greenhouse producers release the appropriate number of rove beetle adults in container greenhouse production systems.

The results of our study indicated that there were no differences in the growth of coleus plants between the two growing media. However, Herrick and Cloyd (2017) found that growing medium type can influence plant growth, although the composition of the two growing media was different. The composition of the two growing media (ProMix BX and Berger BM1) used in the current study was similar (refer to the section "Greenhouse experiment: Varied densities of rove beetle adults"). Nevertheless, the Pro-Mix BX growing medium negatively influenced fungus gnat larval survival; however, the mechanism responsible is not known and requires further investigation. A growing medium that reduces fungus gnat larval survival could be helpful to greenhouse producers who routinely deal with fungus gnats during the growing season.

It should be noted that the laboratory experiment with pasteurized growing medium and coleus roots affected larval survival and subsequent fungus gnat adult captures on the yellow sticky cards compared with pureed potato in both growing media. However, in the greenhouse experiments with unpasteurized growing medium, the Berger BM1 growing medium with coleus roots did not affect fungus gnat larval survival. There was likely more root biomass in the greenhouse containers with coleus than the plugs used in the laboratory experiment. Moreover, this indicates that extrinsic biological factors did not influence the number of fungus gnat adults captured on the yellow sticky cards in the greenhouse experiment. The Berger BM1 growing medium, for instance, had similar numbers of fungus gnat adults captured on the yellow sticky cards.

In conclusion, $D$. coriaria reduced fungus gnat larval populations, regardless of growing medium type, for the two growing media tested. In addition, we found an effect of growing medium in reducing fungus gnat larval populations. Therefore, a plant-protection strategy that uses growing medium and rove beetles may be useful in managing fungus gnats. Based on previous research (Herrick and Cloyd, 2017) and under the parameters of the current study, greenhouse producers should consider the effects of production practices, such as growing medium type, when implementing a biological control program using rove beetle adults to regulate fungus gnat larval populations. 


\section{Literature Cited}

Amoah, B., J. Anderson, D. Erram, J. Gomez, A. Harris, J. Kivett, K. Ruang-Rit, Y. Wang, L. Murray, and J. Nechols. 2016. Plant spatial distribution and predator-prey ratio affect biological control of the twospotted spider mite Tetranychus urticae (Acari: Tetranychidae) by the predatory mite Phytoseiulus persimilis (Acari: Phytoseiidae). Biocontrol Sci. Technol. 26:548-561.

Birken, E.M. and R.A. Cloyd. 2007. Food preference of the rove beetle, Atheta coriaria (Kraatz) (Coleoptera: Staphylinidae) under laboratory conditions. Insect Sci. 14:53-56.

Bykova, O. and S. Blatt. 2018. Effect of soil type on carrot weevil movement behavior. J. Insect Behav. 31:321-333.

Carney, V.A., J.C. Diamond, G.D. Murphy, and D. Marshall. 2002. The potential of Atheta coriaria Kraatz (Coleoptera: Staphylinidae), as a biological control agent for use in greenhouse crops. Intl. Org. Biolog. Integ. Control/West Pal. Reg. Sec. Bull. 25:37-40.

Cheng, L.L., J.R. Nechols, D.C. Margolies, J.F. Campbell, P.S. Yang, C.C. Chen, and C.T. Lu. 2012. Efficacy of the predator Mallada basalis (Neuroptera: Chrysopidae) on Tetranychus kanzawai and Panonychus citri (Acari: Tetranychidae) at different predator:prey release ratios. J. Asia Pac. Entomol. 15:142-146.

Cloyd, R.A. 2000. Fungus gnat and shore fly management strategies: Panel discussion, $\mathrm{p}$. 57-59. In: Proceedings for the 16th Conference on Insect and Disease Management on Ornamentals. Soc. Amer. Florists, Alexandria, VA.

Cloyd, R.A. and A. Dickinson. 2006. Effect of Bacillus thuringiensis subsp. israelensis and neonicotinoid insecticides on the fungus gnat Bradysia sp nr. coprophila (Lintner) (Diptera: Sciaridae). Pest Mgt. Sci. 62:171-177.

Echegaray, E.A., R.A. Cloyd, and J.R. Nechols. 2015. Rove beetle (Coleoptera: Staphylinidae) predation on Bradysia sp. nr. coprophila (Diptera: Sciaridae). J. Entomol. Sci. 50:225-237.

Farhadi, R., H. Allahyari, and H. Chi. 2011. Life table and predation capacity of Hippodamia ariegata (Coleoptera: Coccinellidae) feeding on Aphis fabae (Hemiptera: Aphididae). Biol. Control 59:83-89.

Gardiner, R.B., W.R. Jarvis, and J.L. Shipp. 1990 Ingestion of Pythium spp. by larvae of the fungus gnat Bradysia impatiens (Diptera: Sciaridae). Ann. Appl. Biol. 116:205-212.

Gaudchau, M. 1982. The feeding capacity of syrphid larvae (Syrphus corollae; Dipt.: Syrphidae) as predators of aphids under greenhouse conditions. J. Appl. Entomol. 93:425-429.
Gilkeson, L.A. and S.B. Hill. 1987. Release rates for control of green peach aphid (Homoptera: Aphidae) by the predatory midge Aphidoletes aphidimyza (Diptera: Cecidomyiidae) under winter greenhouse conditions. J. Econ. Entomol. 80:147-150.

Gillespie, D.R. and J.G. Menzies. 1993. Fungus gnats vector Fusarium oxysporum f. sp. radicislycopersici. Ann. Appl. Biol. 123:539-544.

Gouge, D.H. and N.G.M. Hague. 1995. Glasshouse control of fungus gnats, Bradysia paupera, on fuchsias by Steinernema feltiae. Fundam. Appl. Nematol. 18:77-80.

Grez, A.A. and P. Villagrán. 2000. Effects of structural heterogeneity of a laboratory arena on the movement patterns of adult Eriopis connexa and Hippodamia variegata (Coleoptera: Coccinellidae). Eur. J. Entomol. 97:563566

Gustin, R.D. and T.E. Schumacher. 1989. Relationship of some soil pore parameters to movement of first-instar western corn rootworm (Coleoptera: Chrysomelidae). Environ. Entomol. 18:343346.

Harris, M.A., R.D. Oetting, and W.A. Gardner. 1995. Use of entomopathogenic nematodes and a new monitoring technique for control of fungus gnats, Bradysia coprophila (Diptera: Sciaridae), in floriculture. Biol. Control 5:412418.

Hassell, M.P., J.H. Lawton, and J.R. Beddington. 1976. The components of arthropod predation: I. The prey death-rate. J. Anim. Ecol 45:135-164.

Helyer, N., K. Brown, and N.D. Cattlin. 2003. A color handbook of biological control in plant protection. Manson Publishing, London.

Herrick, N.J. and R.A. Cloyd. 2017. Effects of growing medium type and moisture level on predation by adult rove beetle, Dalotia coriaria (Coleoptera: Staphylinidae), on fungus gnat, Bradysia sp. nr. coprophila (Diptera: Sciaridae), larvae under laboratory and greenhouse conditions. HortScience 52:736-741.

Hungerford, H.B. 1916. Sciara maggots injurious to potted plants. J. Econ. Entomol. 9:538-549.

Jarvis, W.R., J.L. Shipp, and R.B. Gardiner. 1993. Transmission of Pythium aphanidermatum to greenhouse cucumber by the fungus gnat $\mathrm{Bra}$ dysia impatiens (Diptera: Sciaridae). Ann. Appl. Biol. 122:23-29.

Kindvall, O., G. Nordlander, and H. Nordenhem. 2000. Movement behavior of pine weevil Hylobius abietis in relation to soil type: An arena experiment. Entomol. Exp. Appl. 95:53-61.
Lindquist, R.K., W.R. Faber, and M.L. Casey. 1985. Effect of various root media and insecticides on fungus gnats. HortScience 20: 358-360.

Lindquist, R.K. 1994. Integrated management of fungus gnats and shore flies, p. 58-67. In: K. Robb (ed.). Proceedings for the 10th Conference on Insect and Disease Management on Ornamentals, 19-21 Feb. 1994, Dallas, Texas. Soc. Amer. Florists, Alexandria, VA.

Little, T.M. and F.J. Hills. 1978. Agricultural experimentation: Design and analysis. John Wiley \& Sons, New York, NY.

MacDonald, P.J. and C.R. Ellis. 1990. Survival time of unfed, first-instar western corn rootworm (Coleoptera: Chrysomelidae) and the effects of soil type, moisture, and soil compaction on their mobility in soil. Environ. Entomol. 19:666-671.

Miklasiewicz, T.J., P.S. Grewal, C.W. Hoy, and V.S. Malik. 2002. Evaluation of entomopathogenic nematodes for suppression of carrot weevil. Biol. Control 47:545-561.

Miller, K.V. and R.N. Williams. 1983. Biology and host preference of Atheta coriaria (Coleoptera: Staphylinidae), an egg predator of Nitidulidae and Muscidae. Ann. Entomol. Soc. Am. $76: 158-161$

Opit, G.P., J.R. Nechols, and D.C. Margolies. 2004 Biological control of twospotted spider mites, Tetranychus urticae Koch (Acari: Tetranychidae), using Phytoseiulus persimilis AthiasHenriot (Acari: Phytoseiidae) on ivy geranium: Assessment of predator release ratios. Biol. Control 29:445-452.

Pacchioli, M.A. and A.A. Hower. 2004. Soil and moisture effects on the dynamics of early instar clover root curculio (Coleoptera: Curculionidae) and biomass of alfalfa root nodules. Environ. Entomol. 33:119-127.

Riis, L. and P. Esbjerg. 1998. Season and soil moisture effect on movement, survival, and distribution of Cyrtomenus bergi (Hemiptera: Cydnidae) within the soil profile. Environ. Entomol. 27:1182-1189.

SAS Institute. 2012. SAS/STAT user's guide Version 9.4. SAS Institute, Cary, NC.

Wilkinson, J.D. and D.M. Daugherty. 1970. The biology and immature stages of Bradysia impatiens (Diptera: Sciaridae). Ann. Entomol. Soc. Amer. 63:656-660.

Wright, E.M. and R.J. Chambers. 1994. The biology of the predatory mite Hypoaspis miles (Acari: Laelapidae), a potential biological control agent of Bradysia paupera (Dipt.: Sciaridae). Entomophaga 39:225-235. 